\title{
Deep Learning based assessment of groundwater level development in Germany until 2100
}

Andreas Wunsch ${ }^{1}$, Tanja Liesch ${ }^{1}$, Stefan Broda ${ }^{2}$ ${ }^{1} \mathrm{KIT}$, ${ }^{2 B G R}$
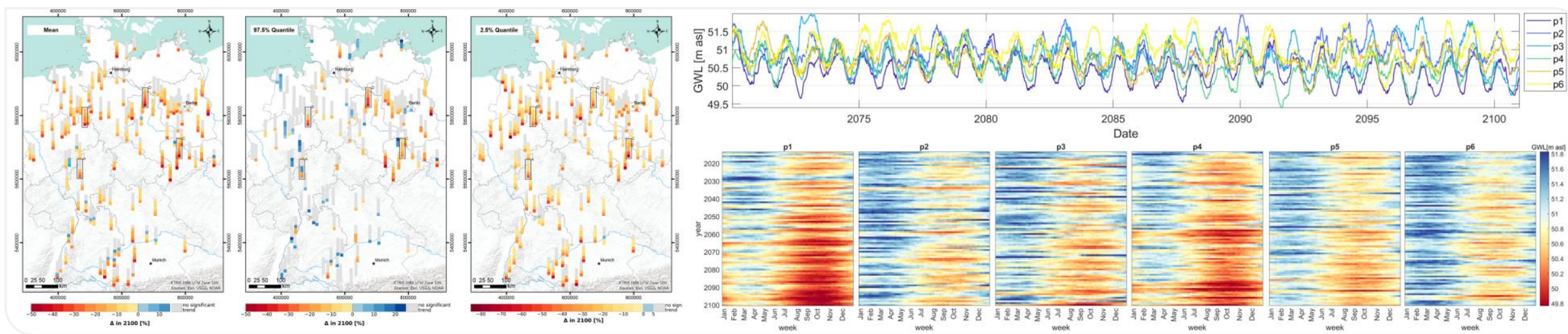


\section{Current Situation in Germany}

- Germany is generally water rich ${ }^{1}$

- water availability per year: 188 billion $\mathrm{m}^{3}$

- less than $13 \%$ are used

- $70 \%$ of drinking water supply from GW and springs ${ }^{2}$

- Hot and dry summers in recent years (esp. 2018-2020)

$\rightarrow$ ongoing exceptional droughts (few recharge and declining groundwater levels)

$\rightarrow$ severe consequences for agriculture and ecology 


\section{Long-Term Climate}

- Simulation of groundwater levels based on climate projection ensemble:

- 118 sites all over Germany

- RCP 8.5 ("business as usual”)

- 6 bias corrected and downscaled projections (5x5 km²)

- $80 \%$ of expected climate signal ("DWD coreensemble")

- Until 2100:

- Total annual precipitation (left): no trend or slight increase except for one projection

- Annual avg. Temperature (right): substantial increase
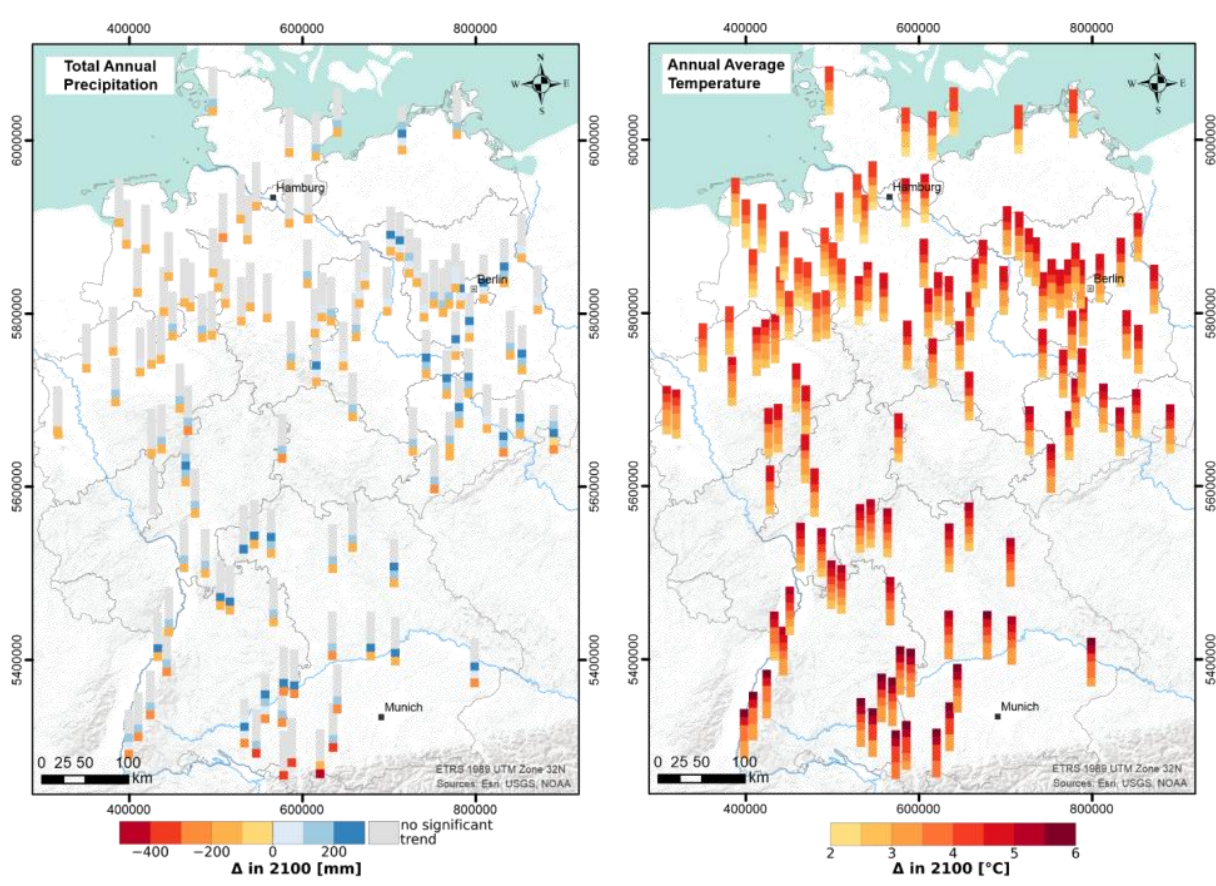


\section{Methods: Model building}
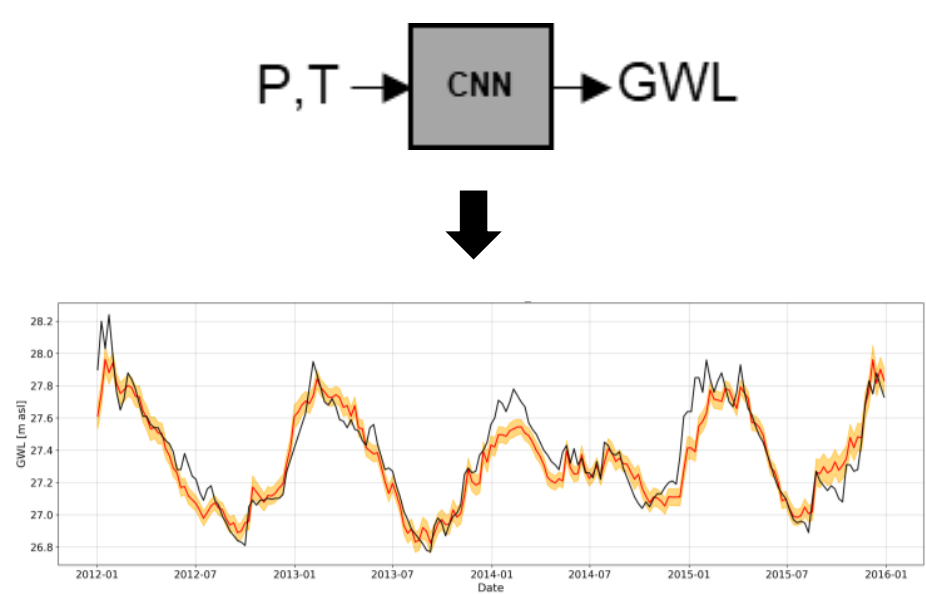

$\downarrow$

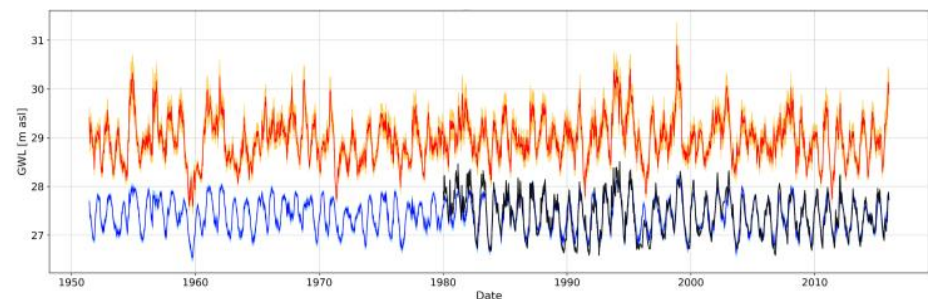

1. Site-specific 1D-CNN Models to predict GWL using (only) $\mathrm{P}$ and $\mathrm{T}$

2. Train, optimize and validate Models in the past (observed climate data), select highly performing models

3. Plausibility checks (artificial extreme climate scenario $\left(\mathrm{T}+5^{\circ} \mathrm{C}, \mathrm{P} \times 4\right)$ and SHAP values)

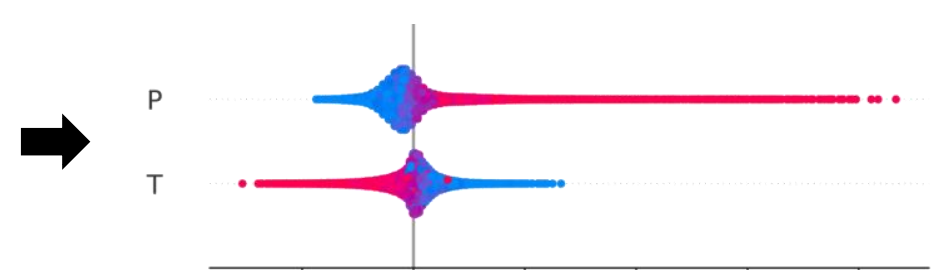




\section{Limitations and Assumptions}

- Highly Performing Models in the past

$\rightarrow$ sites mainly influenced by climate

- Only climatic influences are taken into account

- Basic input-output relationships remain unchanged

- Secondary, mainly anthropogenic effects are neglected!

- We simulate direct climate change effects on GW 


\section{Results: Individual Site, 6 different results}

Individual projection results 2070-2100 (partly diverging)
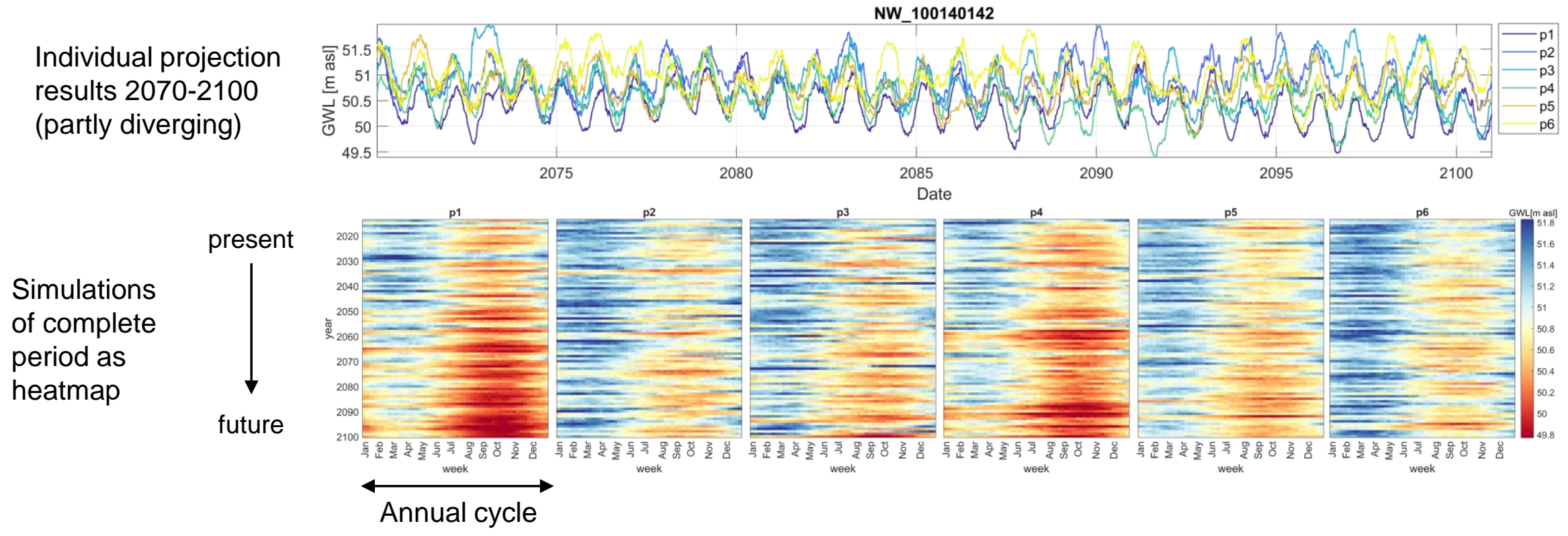


\section{Results: Individual Site, 6 different results}

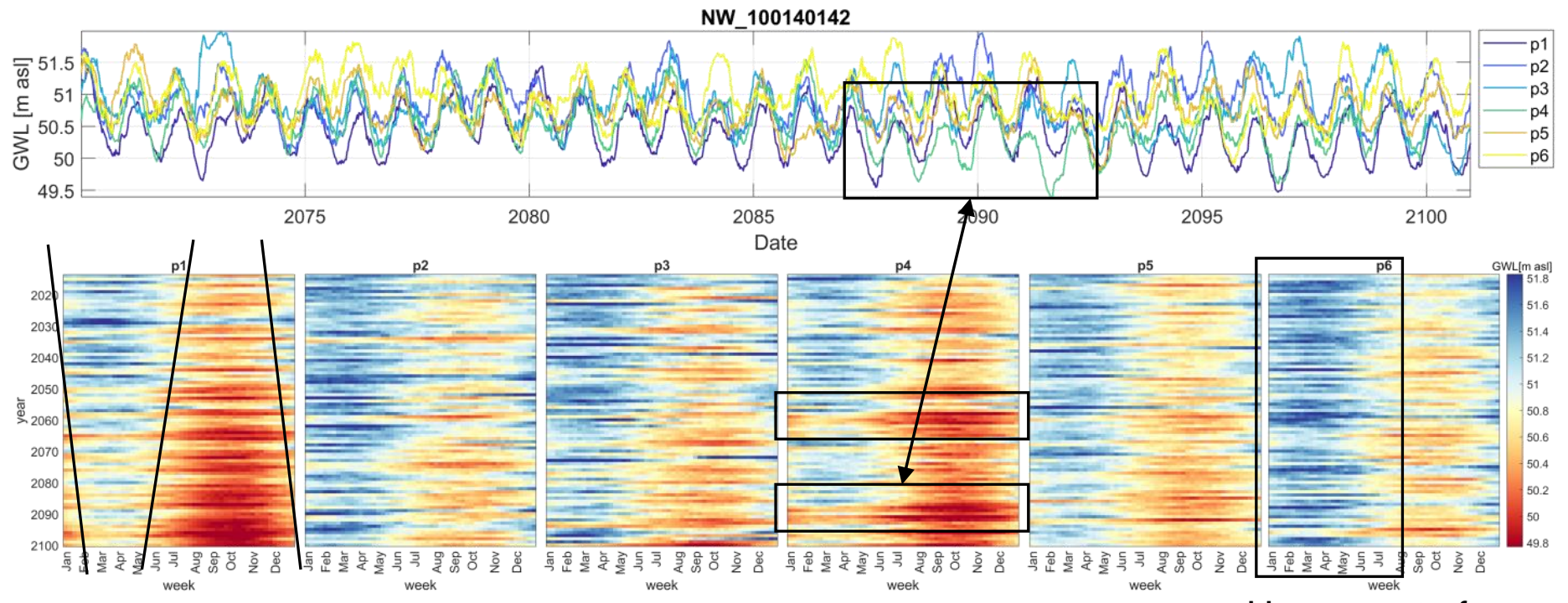

Wet periods (blue): shorter and less wet

Dry periods (red): longer and drier
Especially critical:

Succession of several dry years
Upper part of annual cycle does not necessarily decrease in absolute height (blue tones remain) 


\section{Results: linear trend analyses}

linear trend is based on Mann-Kendall test and Theil-Sen slope

Significant $(p<0.05)$ relative changes [\%] until 2100 - compared to 2014 (start of sim.) and normalized on individual historic range;
Annual $2.5 \%$ quantile

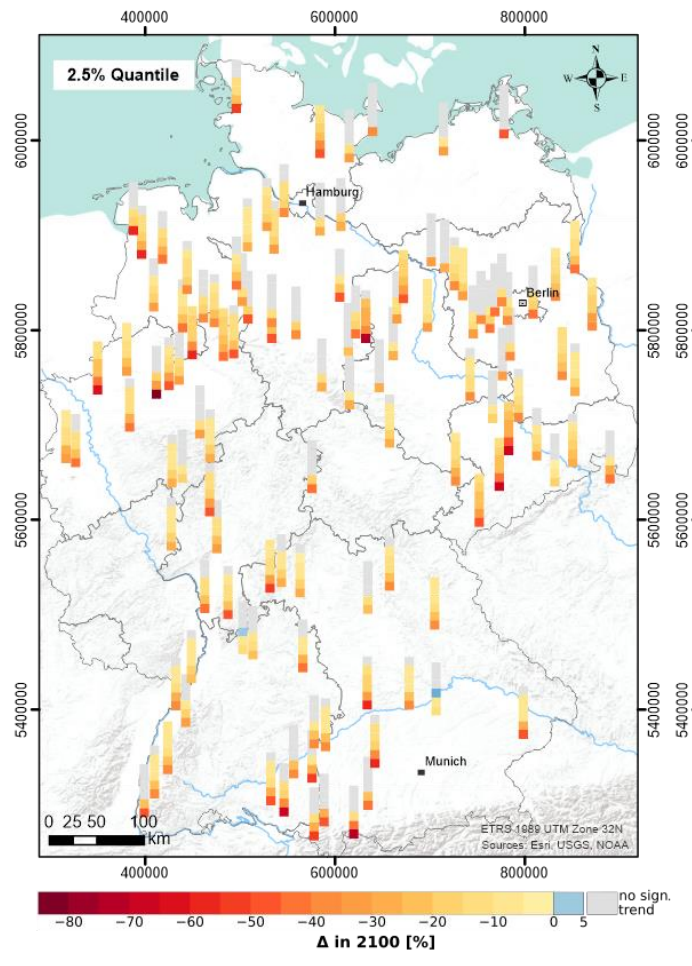

Annual mean

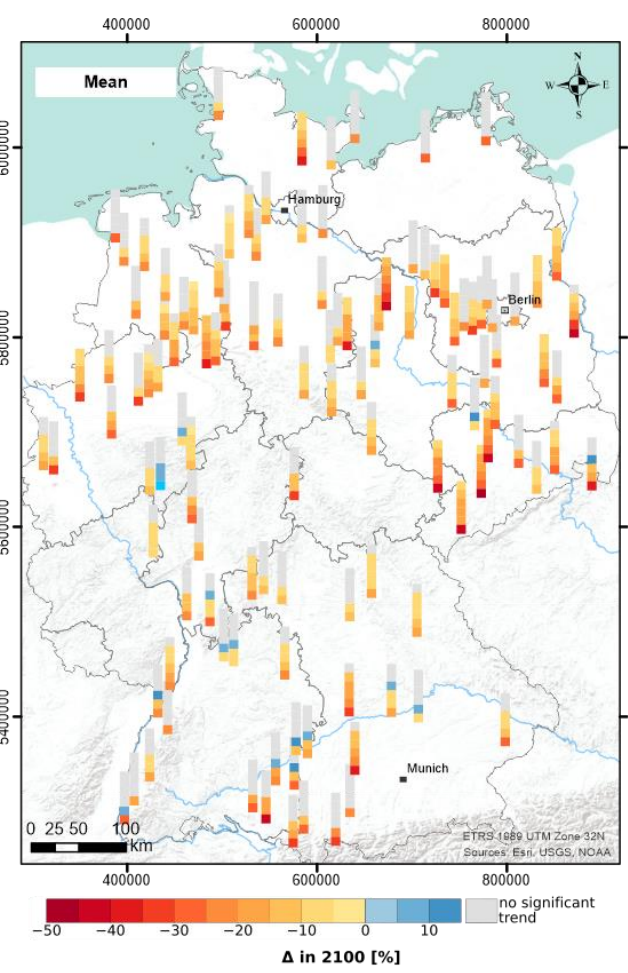

Annual $97.5 \%$ quantile

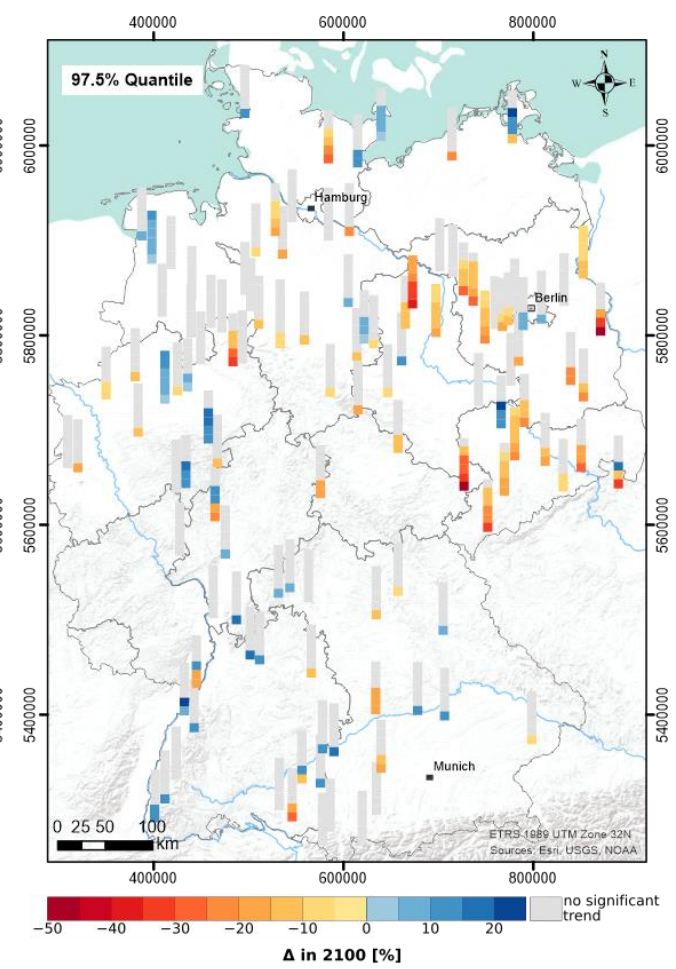




\section{Results: Annual Mean}

linear trend is based on Mann-Kendall test and Theil-Sen slope

Significant $(p<0.05)$ relative changes [\%] until 2100 -

compared to 2014

(start of sim.) and

normalized on

individual historic

range;

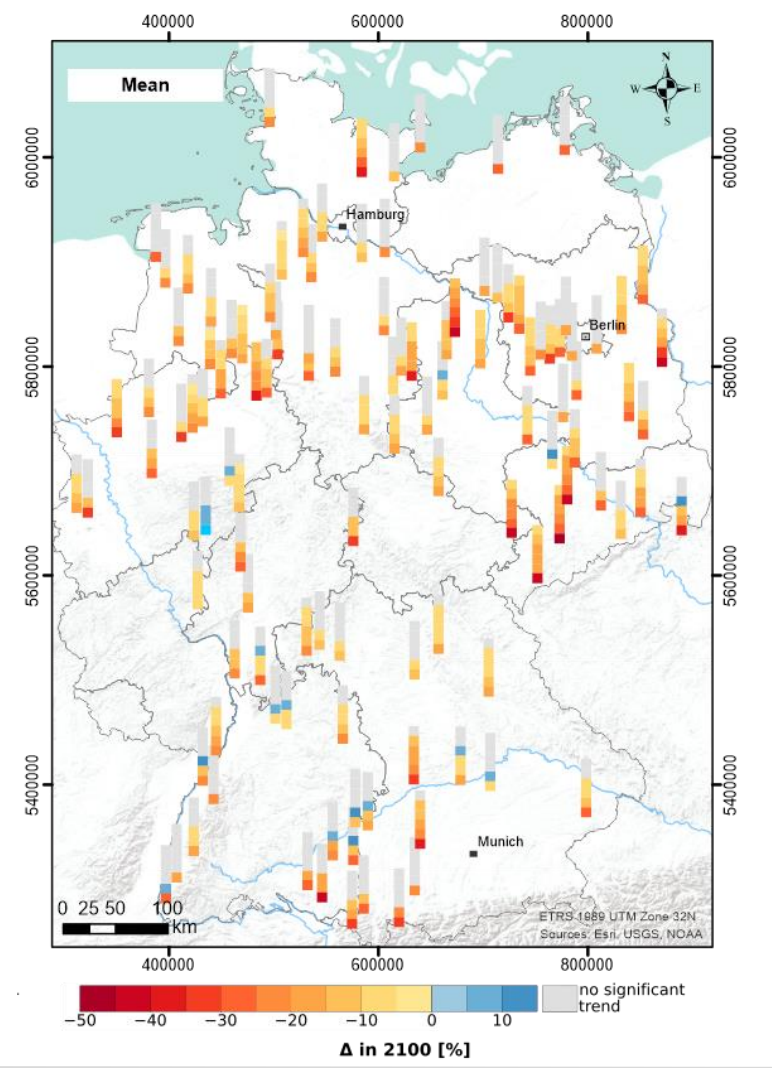

$\Delta$ in $2100[\%]$
Significant Relative Changes of the Mean in $2100(p<0.05)$

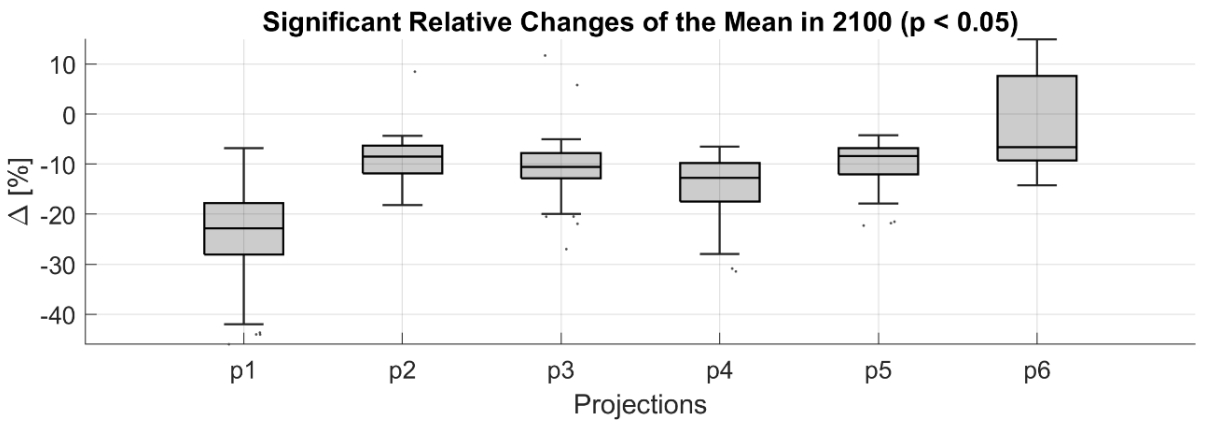

- $54 \%$ significant trends $(\mathrm{p}<0.05)$

- different developments depending on projection

$\rightarrow$ median change between $-23 \%(\mathrm{p} 1)$ and $-6.6 \%$ (p6)

$\rightarrow$ absolute numbers: $-0.1 \mathrm{~m}$ to $-0.4 \mathrm{~m}$

- more and stronger negative trends in northern and eastern Germany

- some opposite trends at single sites 


\section{Results: Annual 2.5\% Quantile}

linear trend is based on Mann-Kendall test and Theil-Sen slope

Significant $(p<0.05)$ relative changes [\%] until 2100 -

compared to 2014 (start of sim.) and normalized on individual historic range;

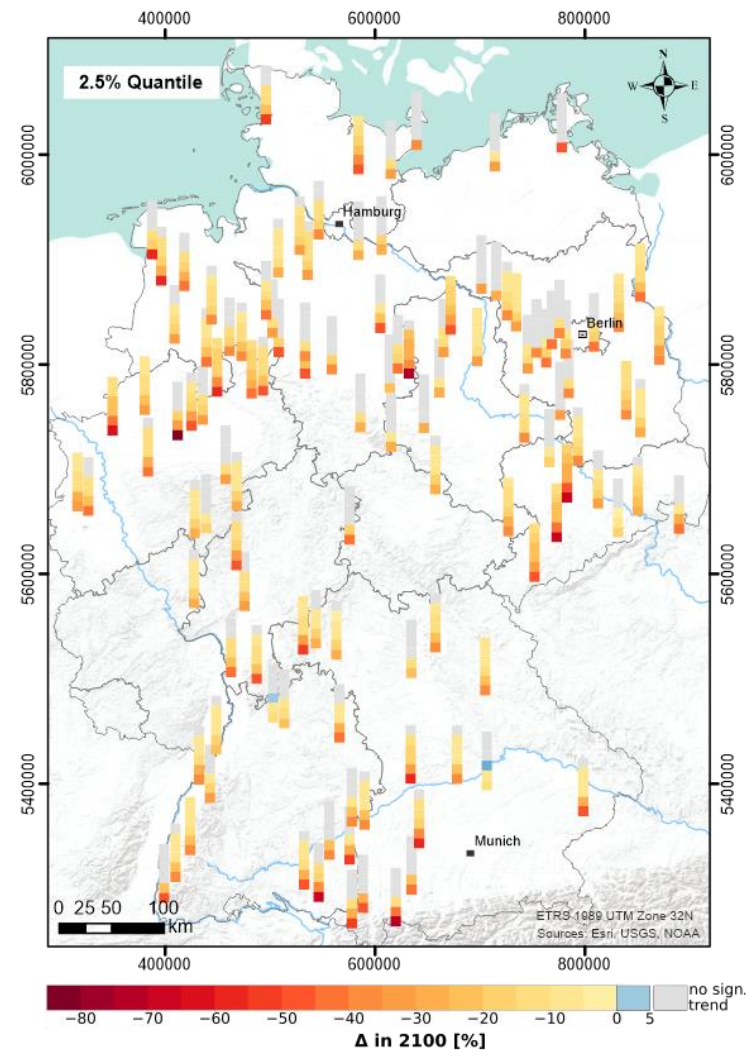

EGU21-9590; HS8.2.2; M.Sc. Andreas Wunsch
- $64 \%$ significant trends

all but one single result: downward trends

trends down to $-81 \%$

- median changes (depending on the projection) between:

$\rightarrow-38 \%$ and $-10 \%$

$\rightarrow$ absolute: $-0.1 \mathrm{~m}$ to $-0.7 \mathrm{~m}$ 


\section{Results: Annual 97.5\% Quantile}

linear trend is based on Mann-Kendall test and Theil-Sen slope

Significant $(p<0.05)$ relative changes [\%] until 2100 -

compared to 2014 (start of sim.) and normalized on individual historic range;

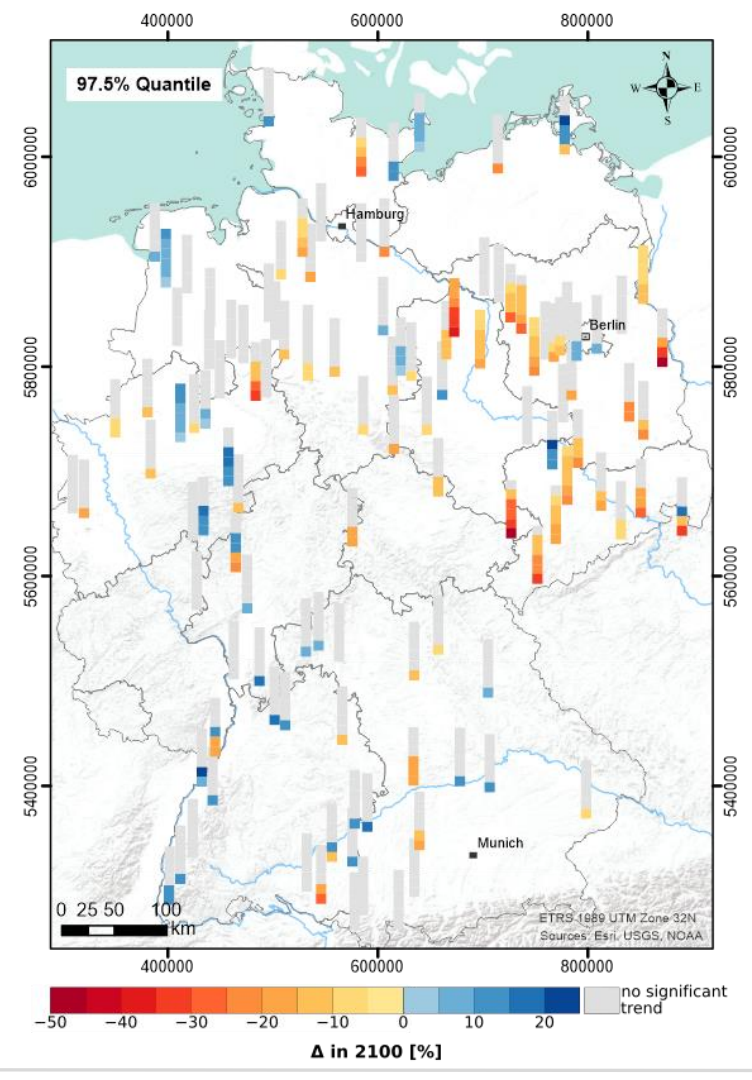

- $>70 \%$ : non-significant

also increasing trends up to $20 \%$

- clear spatial pattern: constant or increasing trends except eastern Germany (declining trends)

- Opposing trends compared to other quantiles $\rightarrow$ increasing variability 


\section{Summary}

- Clear tendency of declining groundwater levels until 2100 in Germany

- Emphasized existing trends: stronger declines in eastern Germany

- Absolute values mostly seem small: order of tens of centimeters

$\rightarrow$ nevertheless critical

$\rightarrow$ amplified by secondary factors (only direct influence projected)

- Only linear trends: obscured patterns of successive dry years, likely to have serious consequences 


\section{Find me on:}

(7) https://github.com/AndreasWunsch

in https://www.linkedin.com/in/andreaswunsch/

https://hydro.agw.kit.edu/21 172.php

\section{Thank you}

https://www.researchgate.net/profile/Andreas-Wunsch

(iD) ORCID: 0000-0002-0585-9549

Email: andreas.wunsch@kit.edu 